\title{
RESENHA DE MISS DOLLAR: STORIES BY MACHADO DE ASSIS
}

\section{REVIEW OF MISS DOLLAR: STORIES BY MACHADO DE ASSIS}

ASSIS, Machado de. Miss Dollar: Stories by Machado de Assis. Edição bilíngue. Organização de Glenn Alan Cheney. Traduzido por Greicy P. Bellin e Ana Lessa-Schmidt. Hanover: New London Librarium, 2016, 525p.

\section{LUANA FERREIRA DE FREITAS}

Universidade Federal do Ceará

Fortaleza, Ceará, Brasil

\section{CYNTHIA BEATRICE COSTA}

Universidade Federal de Santa Catarina

Florianópolis, Santa Catarina, Brasil

\begin{abstract}
A internacionalização da literatura brasileira tem avançadode maneira consistente, o que pode ser atestado, entre outros exemplos, pelo 1 sucesso da recente empreitada de Benjamin Moser, The Complete Stories, com os contos de Clarice Lispector, e pelos dados disponíveis do projeto Conexões Itaú Cultural, que mapeia a divulgação das letras brasileiras no estrangeiro. De acordo com o site do projeto, o escritor brasileiro mais lido, pesquisado e traduzido fora do Brasil é Machado de Assis. ${ }^{1}$

Um dos motivos para o sucesso da recepção de obras brasileiras no exterior e para o crescente número de traduções e retraduções de autores brasileiros fora do Brasil é o Programa de Apoio à Tradução e à Publicaçãode Autores Brasileiros no Exterior promovido pela Fundação Biblioteca Nacional, que já apoiou 910 traduções, de 329 autores diferentes, tendo sido a obra de Machado contemplada 38 vezes. $^{2}$
\end{abstract}

\footnotetext{
${ }^{1}$ Seguido de Clarice Lispector, Guimarães Rosa, Jorge Amado e Graciliano Ramos, para citar apenas os cinco primeiros. Ver http://conexoesitaucultural.org.br/parceiros/.

${ }^{2}$ De acordo com consulta a Fábio Lima, Fundação Biblioteca Nacional.
} 
Pode-se perceber o aumento de interesse em Machado se considerarmos apenas as antologias de contos em que o autor figura na última década no sistema literário anglófono. De 2006 até 2016, Machado apareceu em onze antologias em língua inglesa, seis das quais dedicadas exclusivamente a ele. ${ }^{3}$ Trataremos aqui da mais recente empreitada da contística machadiana em inglês: Miss Dollar: Stories by Machado de Assis, que está entre as contempladas pelo já citado Programa de Apoio à Tradução e à Publicaçãode Autores Brasileiros no Exterior da Biblioteca Nacional.

O livro foi produzido sob a responsabilidade do norte-americano Glenn Alan Cheney, editor-chefe da New London Librarium e, claramente, um admirador da literatura brasileira. Seu interesse tem sido demonstrado pela produção recente da pequena editora, sediada em Connecticut: a antologia machadiana faz parte da Brazil Series da editora New London Librarium, que conta, ainda, com Religions in Rio, edição bilíngue de As religiões no Rio, de João do Rio, traduzido por Ana Lessa-Schmidt; Law of the Jungle: Environmental Anarchy and the Tenharim People of Amazonia, ediçãobilíngue de autoria do próprio Cheney e tradução de Daniela Vidigal; e Quilombo dos Palmares: Brazil's Lost Nation of Fugitive Slaves, também de Cheney. Em 2014, já havia publicado outra coletânea bilíngue de contos machadianos, intitulada Ex-Cathedra, da qual participaram vários tradutores, entre os quais Cheney.A New London Librarium promete em breve o lançamento de mais três títulos brasileiros: The Best Chronicles of Rubem Alves, traduzido por Cheney; Veriginous Life, edição bilíngue de Vida vertiginosa de João do Rio, traduzido por Lessa-Schmidt; e Love: Intransitive Verb, tradução de Amar, verbo intransitivo, de Mário de Andrade, com tradução também de Lessa-Schmidt.

Miss Dollar: Stories by Machado de Assis, com tradução de Greicy Pinto Bellin e Ana Lessa-Schmidt, conta com uma apresentação de Ana Cláudia Suriani da Silva, da University College of London, uma introdução assinada por Greicy P. Bellin e traduzida pelo organizador da antologia, Cheney, euma seleção de dez contos de Machado: "Frei Simão" [Friar Simão], "Confissões de uma viúva moça" [Confessions of a Young Widow], "O carro no 13" [Coach 13], "A mulher de preto" [The Woman in Black], "O segredo de Augusta" [Augusta's Secret], "Miss Dollar", "A parasita azul" [The Blue Parasite], "O relógio de ouro" [The Gold Watch], "Três consequências" [Three Consequences] e Só! [Alone!].

\footnotetext{
3 Dados até 2015, segundo o artigo de Freitas e Costa "Machado contista em antologias de língua inglesa",
} em Cadernos de Tradução, vol. 53, n. 1. 
A seleção de contos apresenta uma faceta diferente do autor brasileiro aos leitores de língua inglesa. A antologia mostra ousadia ao divulgar um Machado em construção. Dos contos selecionados, cinco compõem Contos fluminenses ("Miss Dollar", "A mulher de preto", "O segredo de Augusta", "Confissões de uma viúva moça" e "Frei Simão"), primeira antologia de Machado, que tem sido negligenciada em língua inglesa: dos seus sete contos, apenas dois foram traduzidos até 2014. ${ }^{4}$ De Histórias da meia-noite, temos dois contos traduzidos de seis no total: "A parasita azul" e "O relógio de ouro", sendo que apenas o segundo já havia sido traduzido. ${ }^{5}$ Os outros três contos que figuram na obra não foram antologizados tampouco traduzidos: "O carro $\mathrm{n}^{\circ}$ 13", de 1868; "Três consequências", de 1883, e "Só!", de $1885 .{ }^{6}$

São, assim, sete contos inéditos para o leitor anglófono, uma empreitada admirável, mas exagerada na quarta capa do belo volume de 527 páginas, onde se lê que seriam todos textos inéditos em inglês.

Bellin, na Introdução à antologia, justifica sua seleção de contos chamando a atenção para "a importância destas narrativas para a maturidade literária de Machado. Tal maturidade certamente não foi conquistada de um dia para o outro, e sim por meio de um consciente e constante trabalho". ${ }^{7} \mathrm{O}$ cuidado com a escolha das edições nas quais se basearam as traduções, porém, parece ter sido o principal entre os critérios que nortearam o projeto: as antologistas buscaram na Biblioteca Nacional as versões publicadas originalmente nos periódicos, evitando, assim, discrepâncias "em relação aos conteúdos das narrativas", o que poderia afetar a interpretação e colaborar "para a disseminação de equívocos interpretativos em relação à obra". ${ }^{8}$ Dessa forma, a antologia busca

$[\mathrm{P}]$ ossibilitar aos leitores brasileiros e estrangeiros o acesso ao texto machadiano tal qual ele realmente foi escrito, a fim de que estes mesmos leitores possam compreender o alcance da modernidade representada por um dos maiores escritores da literatura brasileira. ${ }^{9}$

Chama a atenção, no entanto, a opção pelo título: "Miss Dollar" é um dos três contos da antologia que já tinham aparecido em outras traduções para o

\footnotetext{
4 "Frei Simão" em Tales of Old Brazil (2013), e "Miss Dollar" em Midnight Mass and other Stories (2014).

${ }^{5}$ Em Midnight Mass and other Stories (2014).

Ver http://machado.mec.gov.br/contos-avulsos-links-174

http://www.machadodeassis.net/hiperTx_romances/index.asp.

${ }^{7}$ Bellin, Introdução. Miss Dollar: Stories by Machado de Assis, p. 24.

${ }^{8}$ Idem, p. 42.

${ }^{9}$ Ibidem.
} 
inglês, e há apenas dois anos. Trata-se de um dos contos mais conhecidos da fase inicial de Machado, o que pode justificar a escolha.

Outra decisão editorial que pode intrigar o leitor, mas que não só se revela explicável, como também interessante, é a imagem da capa. Trata-sede uma reprodução da pintura Lady and a Greyhound, realizada em cerca de 1895 pelo artista tcheco Václav Brozík (1851-1901). O pintor retrata aqui uma cena claramente europeia, com uma dama vestida para o inverno e um cão de caça - um galgo, especificamente. Quem ler "Miss Dollar" entenderá a referência.

Miss Dollar: Stories by Machado de Assis é bilíngue, o que proporciona ao leitor a possibilidade de cotejar os textos. As traduções não são assinadas individualmente; assim, partimos do pressuposto de que foram feitas todas a quatro mãos. Na antologia, o autor floresce em inglês sobretudo em "Augusta's Secret", em que as tradutoras mantêm o tom cínico e cômico do conto, com acertadas escolhas lexicais que realçam o estilo machadiano.

Os textos em inglês, de uma maneira geral, primam pela legibilidade e acessibilidade do leitor, proporcionando, pois, uma leitura fluida dos contos de Machado. Assim, as tradutoras reorganizam pontuação e estrutura dos períodos, evitando inversões, atualizam o texto e fornecem notas para cada conto. Ao fim de cada, seguem-se fonte original datada do texto e notas detalhadas.

As notas são possivelmente uma das melhores surpresas nessa antologia. Deixando de lado uma ou outra repetição, as notas abrangem aspectos culturais, históricos e geográficos do Brasil e da cidade do Rio de Janeiro, além de fornecerem traduções para fragmentos citados em língua estrangeira, e várias notas são de natureza intertextual. Para uma segunda edição da antologia, talvez valesse a pena incluir notas em português também, uma vez que muitos aspectos abordados ali são nebulosos para o leitor brasileiro atual. Ainda, em relação a uma segunda edição, seria interessante alinhar os textos em português e em inglês e rever a paginação no índice referente ao mapa do Rio de Janeiro e ao fac-símile da Gazeta de Notícias.

Podemos afirmar, para concluir, que Miss Dollar: Stories by Machado de Assis contribui para o crescente reconhecimento de Machado de Assis no sistema literário anglófono e para a divulgação das letras brasileiras no estrangeiro. A iniciativa de Glenn Alan Cheney, de Greicy Pinto Bellin e de Ana Lessa-Schmidt, bem como a aposta da editora New London Librarium na publicação de obras brasileiras, abre caminho para um conhecimento mais completo da trajetória de Machado e seu árduo trabalho ao longo de décadas até se tornar um grande escritor louvado, entre outros, por Susan Sontag. 


\section{Referências}

ASSIS, Machado de. Contos avulsos. Disponível em <http://machado.mec.gov.br/contos-avulsos-links-174>. Acesso em 3 out. 2016.

.Ex Cathedra: Stories by Machado de Assis. Org. de Glenn Alan Chency. Trad. de Laura Cade Brown et al. Hanover (CT): New London Librarium, 2014.

. Midnight Mass and Other Stories. Trad. e ed. de Juan LePuen. Ebook. Amazon, 2014.

. Obra completa. Rio de Janeiro: Nova Aguilar, 1994.

BELLIN, Greicy Pinto. Introdução. Miss Dollar: Stories by Machado de Assis. Edição bilíngue. Organização de Glenn Alan Cheney. Traduzido por Greicy P. Bellin e Ana Lessa-Schmidt. Hanover: New London Librarium, 2016.

CONEXÃO Itaú $\quad$ Cultural. $\quad$ Disponível em $<$ http://conexoesitaucultural.org.br/parceiros/>. Acesso em 3 out. 2016.

LUANA FERREIRA DE FREITAS é doutora em Teoria Literária, pela Universidade Federal de Santa Catarina, e atualmente é professora na Universidade Federal do Ceará, onde atua na área de literatura. É uma das fundadoras e primeira coordenadora da POET - Pós-Graduação em Estudos da Tradução (UFC) e vice-coordenadora do GT de Tradução da Anpoll, gestão 2014-2016. Organizou em conjunto com Walter Carlos Costa o I Colóquio Machado de Assis, Literatura \& Tradução, em abril de 2015, na UFC. Publicou "Sterne em Memórias póstumas de Brás Cubas e Dom Casmurro", Machado de Assis em Linha, v. 7, p. 183-197, 2014; e, em conjunto com Cynthia Beatrice Costa, "Machado contista em antologias em língua inglesa", na Cadernos de Tradução, v. 35, p. 69-85, 2015; e "Casa Velha / The Old House, de Machado de Assis", tradução de Mark Carlyon, na Cadernos de Tradução (UFSC), v. 2, p. 283-292, 2014. E-mail: luanafreitas.luana@gmail.com.

CYNTHIA BEATRICE COSTA possui formação em Comunicação Social, mestrado em Crítica Literária, pela PUC-SP, e doutorado pelo Programa de Pós-Graduação em Estudos da Tradução da Universidade Federal de Santa Catarina (UFSC). É também sócia-editora da Editora Poetisa, especializada em traduções literárias. Em conjunto com a Profa. Dra. Luana Ferreira de Freitas, publicou recentemente "Machado contista em antologias em língua inglesa", na Cadernos de Tradução, v. 35, p. 69-85, 2015, e "Casa Velha / The Old House, de Machado de Assis", tradução de Mark Carlyon, na Cadernos de Tradução (UFSC), v. 2, p. 283-292, 2014. E-mail: cynthia@editorapoetisa.com.br.

Recebido: 19.10.2016

Aprovado: 12.11.2016 